\title{
HYDROMETEOROLOGICAL INTERPRETATION OF ISOTOPIC DATA ON ATMOSPHERIC MOISTURE AND PRECIPITATION
}

\author{
by
}

\author{
R.K. Saxena and E. Eriksson
}

(Division of Hydrology, Uppsala University, Västra Ágatan 24, 75220 Uppsala, Sweden)

\section{ABSTRACT}

The influence of advective and eddy transport of atmospheric moisture on the ${ }^{18} \mathrm{O}$ content of atmospheric vapour and precipitation is discussed. Measurements of the ${ }^{18} \mathrm{O}$ content of atmospheric vapour and precipitation have been carried out since July 1981 in Uppsala, Sweden. The removal of water from atmospheric vapour is accomplished by freezing it out of a stream of air passed at the rate of $601 \mathrm{~h}^{-1}$ through cooling traps maintained at a temperature of $-60^{\circ} \mathrm{C}$. The method is practically non-fractionating. The observed slopes of the regression equations defining the linear relationship between weighted monthly $\delta^{18} \mathrm{O}$ of precipitation and mean monthly temperatures at the ground level agree fairly well with the predicted slopes assuming that the transport of atmospheric moisture is due to eddy motion. Similarly the slope of the linear relationship between $\delta^{18} \mathrm{O}$ in atmospheric vapour and vapour density at ground level is also closely predicted by the eddy transport model. However, if it is assumed that the transport of atmospheric moisture is advective, the predicted slopes are nearly double those observed.

It was also observed that precipitation and atmospheric vapour are in isotopic equilibrium during summer, but not during winter. Results obtained confirm the strong large-scale eddy diffusive nature of the transport of atmospheric moisture.

\section{INTRODUCTION}

The presence of heavy isotopes of oxygen and hydrogen (i.e., ${ }^{18} \mathrm{O}$ and $\left.\mathrm{D}\right)$ in natural waters has been known for a long time. So far as atmospheric moisture is concerned, precipitation in terms of its heavy isotopic species has been intensively studied. Dansgaard (1964) has reviewed some important features about the isotopic variations in precipitation on a global scale, assuming that evaporation and condensation in nature proceed as Rayleigh distillation and condensation processes.

Eriksson (1965) made some attempts to express the isotopic concentrations in precipitation as a function of atmospheric processes which transport atmospheric moisture. $\mathrm{He}$ predicted, on the basis of purely theoretical considerations, that isotopic fractionation is almost half when the transport of atmospheric moisture is due to eddy motion than when it is simply advective. One of the features of Eriksson's analysis was the attempt to describe the isotopic concentrations of atmospheric vapour as a function of precipitable water. However, due to lack of experimental data on the isotopic nature of atmospheric vapour, these ideas remained more or less speculative.

Recently much interest has again been focused on the transport of atmospheric water vapour (Rozanski and Sonntag 1982, Rozanski and others 1982), and its impact on the isotopic composition of precipitation, atmospheric vapour and local climate.

Also, at the Division of Hydrology, Uppsala University, much interest has been devoted to the study of ${ }^{18} \mathrm{O}$ in atmospheric moisture, not only in order to study the atmospheric transport processes but also to understand the effect of isotopic exchange between atmosphere and evaporating bodies. The later process has wide applications in the study of stream-flow separation and lake water budgeting by using stable isotopic tracers. With the above aims in view, monitoring of ${ }^{18} \mathrm{O}$ in atmospheric moisture was started in July 1981 in Uppsala, Sweden.

\section{THE RAYLEIGH PROCESSES}

Water molecules containing ${ }^{18} \mathrm{O}$ or $\mathrm{D}$ have a somewhat lower vapour pressure than ordinary water, which causes a certain fractionation of the isotopes during evaporation and condensation. Water vapour in equilibrium with liquid water has a slight deficit of these isotopes as compared to the liquid phase, i.e.

$$
\mathrm{R}_{\mathrm{l}}=\alpha \mathrm{R}_{\mathrm{v}} \quad \alpha>1
$$

where $R$ is the concentration of heavy isotope in water or vapour phase, $\alpha$ is the fractionation coefficient or the ratio of saturation vapour pressure of $\mathrm{H}_{2} \mathrm{O}$ to that of $\mathrm{H}_{2}{ }^{18} \mathrm{O}$ and the subscripts 1 and $\mathrm{v}$ refer to liquid and vapour phases.

If $M$ is the amount of water vapour with an isotope ratio $R$, then condensation of a small amount $d M$ will remove $\alpha R \mathrm{dM}$ of the isotope from the mass $M$. From the isotope balance we have

$$
\text { or } \begin{aligned}
& d(R M)=\alpha R d M \\
& d R / R=(\alpha-1) d M / M .
\end{aligned}
$$

If $\alpha$ is considered a constant, integration yields

$$
R / R_{0}=\left(M / M_{0}\right)^{(\alpha-1)}
$$

Equation (3) is known as the Rayleigh condensation equation. For evaporation in vacuum, the isotopic content of the remaining mass of water can be obtained from Equation (3) by substituting $1 / \alpha$ for $\alpha$, and the expression then is known as the Rayleigh distillation formula. As a first approximation, we assume that the processes of condensation from vapour in the atmosphere or evaporation from the sea follow the Rayleigh formulae.

\section{ATMOSPHERIC MOISTURE IN OCEANS} CONTINENTAL AREAS: THE ISOTOPIC PICTURE

AND

Craig and Gordon (1965) have given a detailed account of the data on the isotopic composition of marine precipitation over ocean and continental areas. In the trade wind belts the sea-surface layer is slightly enriched in ${ }^{18} \mathrm{O}$ and $\mathrm{D}$ due to high evaporation from the surface. The atmospheric vapour is depleted in ${ }^{18} \mathrm{O}$ relative to sea-water by about $10 \%$. The first condensate from this vapour will be enriched relative to sea-water because condensation occurs at a lower temperature than sea-surface temperature (fractionation increases with decreasing temperature). The vapour during its transport poleward gradually loses water by precipitation and, since precipitation is always enriched relative to vapour, the remaining vapour will gradually become depleted polewards. However, during its passage from trade wind belts polewards, a considerable exchange of water with the sea surface occurs because of rain-outs and evaporation. This exchange varies from place to place and 
complicates the picture, obscuring any simple relation between the isotopic content of vapour and temperature.

Even for continental areas one has to consider oceans as a source of moisture. The coastal precipitation will not differ much from oceanic precipitation in adjacent areas but as the moisture is transferred inland to the continents it will suffer a depletion in its isotopic content. A considerable fraction of the precipitated moisture will return to the atmosphere through evapotranspiration without suffering a change in its isotopic content, as evapotranspiration is practically non-fractionating (Eriksson 1965, Zimmerman and others 1967). Thus in continental areas a somewhat simpler relationship between average isotopic content in precipitation and average temperatures can be expected. Rozanski and others (1982) have reported a higher correlation between deuterium and local temperature as one moves inland.

\section{ADVECTIVE TRANSPORT OF ATMOSPHERIC} MOISTURE

Assuming an advective transport of water vapour on a global scale, isobaric cooling by net radiation loss to space is a possible mechanism for removing water (condensation) from an air mass. This removal is thought to occur at the $850 \mathrm{mbar}$ level, i.e. about $1.5 \mathrm{~km}$ a.m.s.l. in the cloud structure. We now define the term $\delta$ which describes the per mille deviation of a sample $R$ relative to the standard mean ocean water (SMOW), i.e.

i.e.

$$
8 \%=1000\left(\mathrm{R}-\mathrm{R}_{\mathrm{st}}\right)
$$

$$
1+\delta^{\prime}=\mathrm{R} / \mathrm{R}_{\mathrm{st}},
$$

where $\delta^{\prime}=\delta / 1000$, then

$$
\mathrm{dD} / \mathrm{R}=\mathrm{d} \delta^{\prime} /\left(1+\delta^{\prime}\right)
$$

Substituting Equation (4) in Equation (2) and taking the temperature derivative

$\mathrm{d}^{\prime} / \mathrm{dT}=(\alpha-1)\left(1+\delta^{\prime}\right) \mathrm{d}(\operatorname{lnM}) / \mathrm{dT} \approx(\alpha-1) \mathrm{d}(\operatorname{lnM}) / \mathrm{dT}$

where $T$ is the absolute temperature in $\mathrm{K}$. At the 850 mbar level the saturation mixing ratio $\mathrm{S}$ in $\mathrm{gkg}^{-1}$ is related to temperature as (c.f. Van't Hoff's equation)

$$
\ln (\mathrm{S})=21.1-5347 / \mathrm{T}
$$

in the range 303 to $293 \mathrm{~K}$ ( 30 to $20^{\circ} \mathrm{C}$ ).

With the temperature derivative the above becomes

$$
\mathrm{d} \ln (\mathrm{S}) / \mathrm{dT}=5347 / \mathrm{T}^{2}
$$

Combining Equations (5) and (6) and using $\mathrm{d}(1 \mathrm{nS})=$ $\mathrm{d}(\mathrm{lnM})$, we get

$$
\mathrm{d}^{\prime} / \mathrm{dT} \approx(\alpha-1) 5347 / \mathrm{T}^{2}
$$

Equation (7) describes the temperature dependence of $\delta$ values in precipitation provided that the water cycle in nature is a simple Rayleigh process.

$$
\begin{aligned}
& \text { Now from Equations (2) and (4) we get } \\
& \mathrm{d} \delta^{\prime} /\left(1+\delta^{\prime}\right)=\mathrm{dR} / \mathrm{R}=(\alpha-1) \mathrm{dM} / \mathrm{M} \\
& \text { or } \mathrm{d} \delta^{\prime}=(\alpha-1)\left(1+\delta^{\prime}\right) \mathrm{dM} / \mathrm{M}
\end{aligned}
$$

and upon integration

$$
\delta^{\prime}=(\alpha-1) 1 \mathrm{nM}+\mathrm{C}
$$

The value of $\alpha$ should correspond to the mean temperature of condensation. However, in the present calculations, $\alpha$ at mean surface temperature has been used, as the mean condensation temperature is supposed to vary parallel to mean surface temperature (Dansgaard 1964).
Equation (9) relates the $\delta$ value of atmospheric vapour to $M$ which in fact is the vapour density at the 850 mbar level. In our experiment, vapour density $\rho\left(\mathrm{gm}^{-3}\right)$ was observed at $5 \mathrm{~m}$ height above ground level. For the sake of simplicity $\rho$ replaces $M$ in actual calculations, although $\rho$ is an exponential function of altitude.

\section{EDDY TRANSPORT OF ATMOSPHERIC MOISTURE}

The poleward movement of water vapour can be considered as a large-scale eddy diffusion process. The vertical transport is also an eddy diffusion process although on a different scale. The zonal transport, however, is a mixture between large-scale eddy diffusion and advection.

In the absence of horizontal gradients in the $\delta$ value of water vapour and M, Eriksson (1965) found that

$$
\mathrm{dR} / \mathrm{R}=\mathrm{d} \delta^{\prime} /\left(1+\delta^{\prime}\right)=(\sqrt{ } a-1) \mathrm{dM} / \mathrm{M} .
$$

This is similar to Equation (8), except that $\sqrt{ } \alpha$ appears instead of $\alpha$.

Hence, in the case of eddy transport of atmospheric moisture, Equation (7) and (9) take a new form, i.e.

$$
\mathrm{d} \delta^{\prime} / \mathrm{dT} \approx(\sqrt{ } \propto-1) 5347 / \mathrm{T}^{2}
$$

and

$$
\delta^{\prime} \approx(\sqrt{ } a-1) 1 n M+C .
$$

The corresponding numerical values obtained from the above equations will thus be roughly half of the values obtained from the advective transport of moisture.

\section{EXPERIMENTAL MONITORING OF ${ }^{18} \mathrm{O}$ IN ATMOSPHERIC VAPOUR}

In order to trace the short-term variations of ${ }^{18} \mathrm{O}$ in atmospheric vapour, a suitable method ensuring a continuous sampling of vapour is necessary. It is also required that a given mass of vapour should be condensed completely, since any loss of vapour will cause an isotopic fractionation of the condensed mass. With this in mind, sampling is performed in the following way. Air is sucked at a rate of $601 \mathrm{~h}^{-1}$ by a membrane pump through two glass traps connected in series and continuously kept at $-60^{\circ} \mathrm{C}$ by an electric compressor. After an interval of $24 \mathrm{~h}$, the glass traps are taken out and allowed to thaw. Liquid water from both the traps is mixed thoroughly, though the amount of water in the second trap is less than $0.1 \%$ of the first.

The residual saturation vapour pressure of water is 1 $\mathrm{Pa}$ at $-60^{\circ} \mathrm{C}$. Thus theoretically some vapour will suffer only partial condensation, leading to a small enrichment of the condensed mass. In order to test the magnitude of such an error, dry nitrogen was bubbled through $15 \mathrm{~g}$ of water of known $\delta$ value. The stream of nitrogen and moisture was passed through the same cold traps (kept at $-60^{\circ} \mathrm{C}$ ) at a rate of $60 \mathrm{l} \mathrm{h}^{-1}$. It took almost $24 \mathrm{~h}$ to bubble $15 \mathrm{~g}$ water to dryness, which is also the time required for the regular air sampling by suction. The glass traps were thawed, weighed and it was found that there was practically no loss of vapour during several trials. The $\delta^{18} \mathrm{O}$ of the recovered water deviated from its true value by $\pm 0.1 \%$, which is also the measurement error of the mass spectrometer. From the above checks it was concluded that no correction is needed for the $\delta^{18} \mathrm{O}$ of recovered moisture.

Cooling of the traps by a compressor was preferred instead of the usual freezing mixtures (dry ice + alcohol) as they require constant and laborious care. They also suffer from temperature fluctuations. Thoma and others (1979) have reported yet another method based on absorption of moisture on molecular sieves. This method is amenable to deuterium analysis, but fails in the case of ${ }^{18} \mathrm{O}$, as the oxygen atoms in the sieve begin to exchange ${ }^{18} \mathrm{O}$ with that in the vapour.

Sampling for ${ }^{18} \mathrm{O}$ was started in Uppsala in July 1981 on a daily basis during the summer months and on a $48 \mathrm{~h}$ basis during winter. Data on the average daily ground-level temperature, relative humidity and precipitation were obtained from a meteorological station, situated $3 \mathrm{~km}$ from the sampling site. Uppsala is a few tens of metres a.s.1. 
TABLE I. COMPARISON BETWEEN OBSERVED AND CALCULATED REGRESSION LINE SLOPES FOR THE $\sigma^{18} \mathrm{O}$-TEMPERATURE RELATIONSHIP IN PRECIPITATION

\begin{tabular}{lcccc} 
Period & $\begin{array}{c}\text { Observed } \\
\text { slope }\end{array}$ & \multicolumn{2}{c}{$\begin{array}{c}\text { Calculated slopes from } \\
\text { advective model }\end{array}$} & $\begin{array}{c}\text { Mean ground level } \\
\text { eddyperature in }{ }^{\circ} \mathrm{C}\end{array}$ \\
Summer & 0.17 & 0.57 & 0.28 & 13 \\
Winter & 0.32 & 0.8 & 0.38 & 0 \\
1982 & 0.19 & 0.78 & 0.32 & 5
\end{tabular}

${ }^{18} \mathrm{O}$ of water samples is measured on a ratio type mass spectrometer after equilibration of $5 \mathrm{ml}$ water with $\mathrm{CO}_{2}$. The ${ }^{18} \mathrm{O}$ contents are expressed as $\delta^{18} \mathrm{O}$, i.e. the per mille deviation from the reference standard (SMOW).

\section{RESULTS AND DISCUSSIONS}

\section{1. $\underline{\delta}^{18} \mathrm{O}$-temperature relationship in precipitation}

In order to bring out the seasonal effects clearly, the precipitation data have been divided into summer (May to October) and winter (November to April) periods. Mean monthly temperatures $\mathrm{T}$ at ground level and weighted monthly $\delta^{18} \mathrm{O}$ of precipitation observed for three years were used to obtain the following regression equations:

$$
\begin{array}{ll}
\delta^{18} \mathrm{O}=0.17 \mathrm{~T}-66.2 \text { summer } & \mathrm{r}^{2}=0.44 \\
\delta^{18} \mathrm{O}=0.32 \mathrm{~T}-109.6 \text { winter } & \mathrm{r}^{2}=0.65 \\
\delta^{18} \mathrm{O}=0.19 \mathrm{~T}-73.2 \text { complete year } 1982 \mathrm{r}^{2}=0.76
\end{array}
$$
and

where $r^{2}$ is the coefficient of determination which is the square of the correlation coefficient.

Slopes of the observed regression lines and theoretical values of slopes obtained from advective and eddy transport models Equations (7) and (11) are shown in Table I. A fairly good agreement between observed and theoretical slopes emerges, when the eddy transport of atmospheric moisture is assumed. In the advective approach the slopes are nearly double the observed values.

\section{$7.2 \delta^{18} \mathrm{O}$ of atmospheric vapour in relation to water vapour} density

Taking the monthly mean of rainy days, the regression equation is

$$
\delta^{18} \mathrm{O}_{\text {vap }}=4.32(\ln \rho)-28.2 \quad\left(\mathrm{r}^{2}=0.72\right)
$$

and for the whole period, including non-rainy days, it is

$$
\delta^{18} \mathrm{O}_{\text {vap }}=4.43(\ln \rho)-28.1 \quad\left(\mathrm{r}^{2}=0.83\right) .
$$

Now, if the advective transport is assumed (Equation (9)), then the slope is $10.86\left(\alpha=1.0111\right.$ at $0^{\circ} \mathrm{C}$ and mean $\delta^{18} \mathrm{O}_{\text {vap }}=-20.99^{\circ} \%$ o) and is more than double the observed values. On the other hand, recourse to the eddy transport model (Equation (12)) yields the slope $=5.41$ at $0{ }^{\circ} \mathrm{C}$, the mean $\delta$ value of vapour being the same as above.

It is obvious from the above that the eddy transport model yields more realistic values of the slopes, which agree quite well with those observed. The $\delta$ vapour and atmospheric water are also well correlated (Fig.1). An interesting feature is that the value for $\mathrm{r}^{2}$ for the whole period is higher than that on rainy days. Perhaps the large number of observations in the whole period offers better statistics.

\subsection{Atmospheric vapour and precipitation: the $\delta$ relationship} During rainy days in the summer period the mean difference between the $\delta$ values of atmospheric vapour and precipitation varies between 9 to $10 \%$. If we assume that rain and vapour are in isotopic equilibrium then their $\delta$ value difference should be about $9 \%$, considering the ground-level temperature to be $20^{\circ} \mathrm{C}$. Thus it is tempting to believe that in summer, rain and vapour, at least at ground level, are in isotopic equilibrium with each other. This

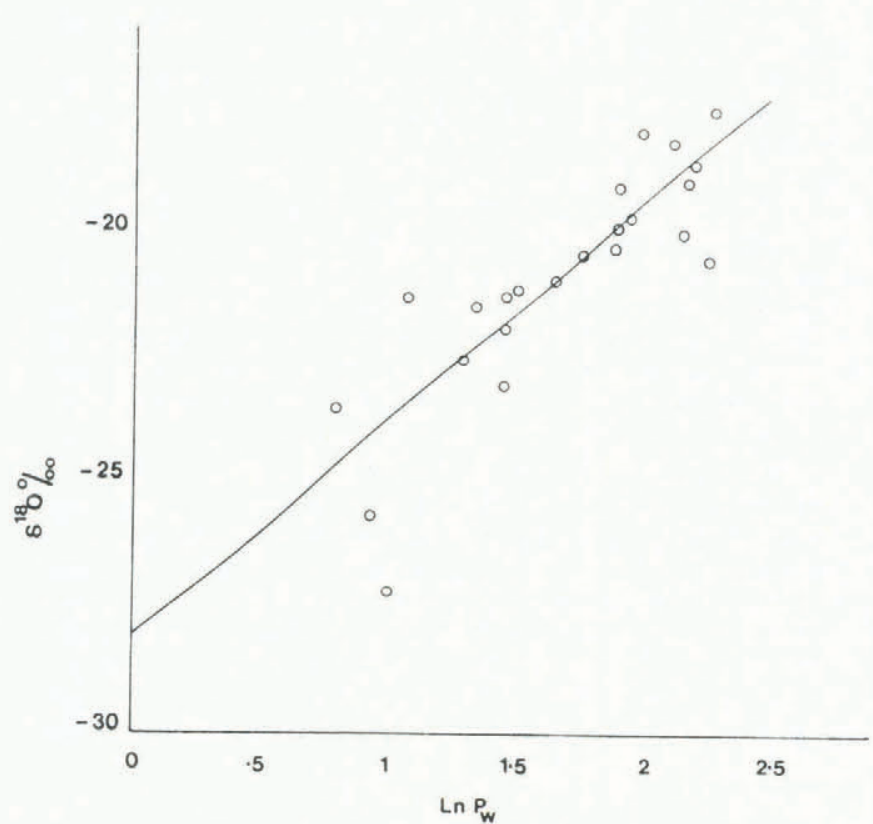

Fig.1. Monthly mean ${ }^{18} 0$ content of atmospheric vapour $\left(8^{\circ} \%\right.$ o $)$ versus natural logarithm of vapour density $\rho\left(\mathrm{g} \mathrm{m}^{-3}\right)$ at ground level observed on rainy days.

shows that raindrops evaporate and exchange considerably below the cloud layers even in north European climates. So far this process was thought to be of some consequence in warm and arid conditions only. Similar conclusions have also been drawn by Rozanski and others (1982), on the basis of $\delta \mathrm{D}-\delta^{18} \mathrm{O}$ relationships in summer precipitation in Europe.

However, during the winter period when the temperature is always below $0^{\circ} \mathrm{C}$, the difference between precipitation and vapour 8 values is about 7 to $9 \%$. This difference is rather small considering that ice and vapour in isotopic equilibrium with each other at $0{ }^{\circ} \mathrm{C}$ will differ by $15 \%$ in their $\delta$ values, and by $16 \%$ at $-10{ }^{\circ} \mathrm{C}$. Obviously vapour and precipitation are not in isotopic equilibrium in winter.

It is quite likely that snow and the surrounding vapour do not get sufficient time for equilibration as new air masses of varying $\delta$ values coming from the Atlantic and from central and southern Europe keep changing the isotopic picture.

\section{CONCLUDING REMARKS}

${ }^{18} \mathrm{O}$ data obtained on atmospheric water vapour confirm the strong large-scale eddy-diffusive nature of water vapour transport in the atmosphere, at least at high latitudes. It is apparent that more information is needed on the vertical distribution of isotopic contents of atmospheric vapour. Previous assumptions that precipitation and atmospheric vapour are in isotopic equilibrium at ground level is true at least for the summer months.

\section{ACKNOWLEDGEMENTS}

The authors wish to acknowledge financial support from the Swedish Natural Science Research Council. Thanks 
are due to Professor Lars Bengtsson and $\mathrm{Mr}$ Allan Rodhe for their useful comments and help in the preparation of the text.

\section{REFERENCES}

Craig H, Gordon L I 1965 Deuterium and oxygen 18 variations in the oceans and the marine atmosphere. In Tongiorgi E (ed) Stable istotopes in oceanographic studies and paleotemperatures, Spoleto, 1965. Pisa, Consiglio Nazionale delle Ricerche. Laboratorio di Geologia Nucleare: 9-130 (Spoleto Conferences in Nuclear Geology) Dansgaard W 1964 Stable isotopes in precipitation. Tellus 16(4): 436-468

Eriksson E 1965 Deuterium and oxygen 18 in precipitation and other natural waters; some theoretical considerations. Tellus 17(4): 498-512

Rozanski K, Sonntag C 1982 Vertical distribution of deuterium in atmospheric water vapour. Tellus 34(2): 135-141

Rozanski K, Sonntag C, Münnich K O 1982 Factors controlling stable isotope composition of European precipitation. Tellus 34(2): 142-150

Thoma G, Esser N, Sonntag C, Weiss W, Rudolph J, Lévêque P 1979 New technique of in-situ soil moisture sampling for environmental isotope analysis applied at Pilat sand dune near Bordeaux HETP modelling of bomb tritium propagation in the unsaturated and saturated zones. In Isotope hydrology 1978. Proceedings of an international symposium on isotope hydrology... held in Neuherberg, 19-23 June 1978. Vol 2. Vienna, International Atomic Energy Agency: 753-766 (Proceedings Series)

Zimmerman U, Ehhalt D, Münnich K O 1967 Soil-water movement and evapotranspiration; changes in the isotopic composition of the water. In Isotopes in hydrology. Proceedings of the symposium on isotopes in hydrology held...in Vienna, 14-18 November 1966. Vienna, International Atomic Energy Agency: 567-584 (Proceedings Series) 